\title{
Allometry for Juvenile Trees in an Amazonian Forest after Wind Disturbance
}

\author{
Gabriel Henrique Pires de Mello RIBEIRO ${ }^{1 *}$, Rempei SUWA ${ }^{2 *}$, \\ Daniel Magnabosco MARRA ${ }^{1,3,4}$, Adriano José Nogueira LIMA ${ }^{1}$, \\ Takuya KAJIMOTO ${ }^{5}$, Moriyoshi ISHIZUKA ${ }^{5}$ and Niro HIGUCHI ${ }^{1}$ \\ ${ }^{1}$ Tropical Forestry Department, National Institute for Amazon Research (PO Box 478, 69011-970 \\ Manaus-AM, Brazil) \\ ${ }^{2}$ Forestry and Forest Products Research Institute, Kansai Research Center (Kyoto, Kyoto 612-0855, \\ Japan) \\ ${ }^{3}$ Department of Biogeochemical Processes, Max Planck Institute for Biogeochemistry (07745 Jena, \\ Germany) \\ ${ }^{4}$ University of Leipzig, Special Botany and Functional Diversity department (04103, Leipzig, \\ Germany) \\ ${ }^{5}$ Forestry and Forest Products Research Institute (Tsukuba, Ibaraki 305-8687, Japan)
}

\begin{abstract}
Allometric models to estimate the aboveground mass $A G M$, belowground mass $B G M$ and total mass $T M$ of juvenile trees (stem diameter at breast height $D B H \leq 5 \mathrm{~cm}$, tree height $H \geq 30 \mathrm{~cm}$ ) in open-canopy terra-firme forests after wind disturbance were developed in the Amazon. For comparison, the allometric models were also developed for a closed-canopy terra-firme forest. After six models had been compared in each forest type, the model with diameter at ground basis $D G B$ and $H$ was selected as the best for estimating $A G M$ and $T M$, and the model with diameter at ground basis $D G B$ as a single variable was selected as the best for estimating $B G M$ considering the adjusted coefficient of determination and standard deviation of the mean. Models based on the diameter at breast height $D B H$ showed poor correlation with each biomass component compared with those based on $D G B$ for the open-canopy forest. The juvenile trees in the open-canopy forest showed higher $A G M$ and $H$ at a given $D G B$ than in the closed-canopy forest, while the $D G B-B G M$ relationships did not differ significantly between the open- and closed-canopy forests. It was concluded that the allometric models used to estimate $A G M$ and $T M$ were unique to each forest type. This would be because light-demanding species show higher allocation to $A G M$ than $B G M$ to be advantageous for competition for light by achieving rapid growth in height.
\end{abstract}

Discipline: Forestry and forest products

Additional key words: biomass allocation pattern, natural regeneration, wind disturbances

\section{Introduction}

A better understanding along the entire life cycle of forest biomass is required to precisely quantify carbon stocks on a regional and national scale. In inventories, it is often assumed that juvenile trees, which are defined as those with a stem diameter at breast height $D B H \leq 5 \mathrm{~cm}$ and tree height $H>30 \mathrm{~cm}$ in the present study, contribute little to total forest biomass and thus often tend to go unmeasured ${ }^{3}$.
However, their contribution depends on the successional stage of the stand ${ }^{3}$. In particular, widespread areas of the Amazon are affected by wind disturbance, the impact of which is significant when evaluating forest dynamics and related carbon dynamics in this region ${ }^{5}$. Therefore, there would be a need to account for rapid forest growth during the initial succession stage caused by wind disturbance when evaluating carbon dynamics in Amazonian forests.

To evaluate carbon dynamics, allometric models for estimating biomass in field studies are essential. In the

This study was supported by the Research Support Foundation of the Amazon State (FAPEAM), the Amazon Wood project of the National Institute of Science and Technology (INCT), and the Science and Technology Research Partnership for Sustainable Development Program of the Japan Science and Technology Agency (JST) and the Japan International Cooperation Agency (JICA).

*Corresponding author: e-mail gabrielgiga@gmail.com (G. H. P. M. Ribeiro) or swrmp2005@yahoo.co.jp (R. Suwa)

Received 4 January 2013; accepted 13 September 2013. 
Central Amazon, although some allometric models have been reported to estimate biomass in old growth and secondary forests $^{16}$, they excluded juvenile trees.

The objectives in the present study were (1) to develop allometric models for estimating biomass for juvenile trees in open-canopy terra-firme forest after wind disturbance, and (2) compare the developed allometric models with those for juvenile trees from a closed-canopy terra-firme forest to elucidate the generality of the developed models.

\section{Materials and Methods}

\section{Study sites}

The study site is located at an EEST - Experimental Station of Forest Management - (hereinafter referred to as ZF2 site) operated by the National Institute for Amazon Research, Brazil ( $\left.2^{\circ} 36^{\prime} \mathrm{S} 11^{\circ} 35^{\prime} \mathrm{W}\right)$. Some areas dominated by "terra-firme" forests on plateaus were significantly disturbed by high-velocity downburst winds in Jan. 2005 (see a previous study ${ }^{11}$ for details). For comparison, we also sampled in an undisturbed closed-canopy terra-firme forest on a plateau $\left(0^{\circ} 7^{\prime} \mathrm{S} 67^{\circ} 3^{\prime} \mathrm{W}\right)$ at São Gabriel da Cachoeira in Amazonas state (hereinafter referred to as SG site) ${ }^{10}$.

\section{Tree individual sampling}

During Jul. 2008 and Nov. 2009, 504 juvenile trees $(H$ $>30 \mathrm{~cm}$ and $D B H \leq 5$ ) were sampled from open-canopy terra-firme forest at the ZF2 site, and all samples were collected in pits and the mounds of uprooted trees created by the downburst winds in Jan. 2005. Furthermore, the sample trees were divided into three size categories including small$(n=289, H<1 \mathrm{~m})$, middle- $(n=128,1 \mathrm{~m}<H<2 \mathrm{~m})$ and large- $(n=87,2 \mathrm{~m}<H)$ sized juvenile trees. All juvenile trees were measured in terms of $T M$, with $A G M$ and $B G M$ separately measured for only 215 samples, including mid- and large-sized juvenile trees $(n=128$ and 87$)$ respectively. Attempts were made to identify all trees at genus level according to the APG III ${ }^{1}$ and 90 genera were recorded $(n=476)$. The five dominant genera were Miconia $(n=50$ including Bellucia grossularioides (L.) Triana), Goupia ( $n=$ 38 including Goupia glabra Aubl.), Protium ( $n=37)$, Inga $(n=17)$ and Pourouma $(n=17)$. The species included in the five dominant genera are frequently observed in the early stage of succession, and G. glabra and B. grossularioides were reportedly the main components in the disturbed terra-firme forests ${ }^{12}$. Furthermore, for comparison and to test the generality of the developed allometric models, 50 samples were also collected from a closed-canopy terrafirme forest at the SG site from Sep. to Oct. $2010(n=50$, $D B H \leq 5 \mathrm{~cm})$. All juvenile trees in the SG site were measured in TM, $A G M$ and $B G M$. Among the 47 trees, 22 genera were recorded, of which the five dominant genera were Iryanthera $(n=8)$, Pterocarpus $(n=4)$, Pouteria $(n=4)$,

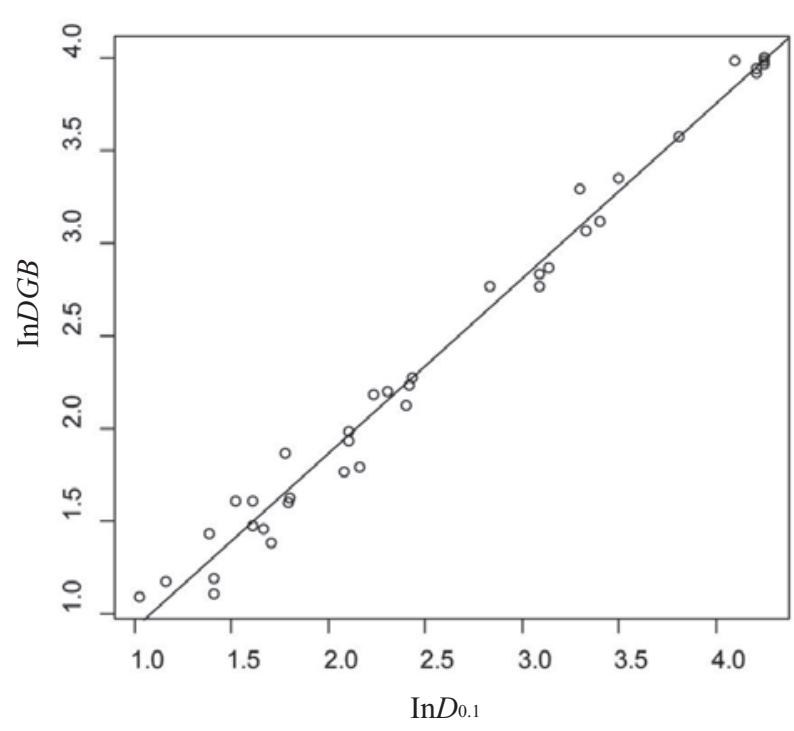

Fig. S1. The relationship between logarithms of diameter at $10 \%$ of tree height $D_{0.1}[\mathrm{~mm}]$ and diameter at ground basis $D G B[\mathrm{~mm}]$ for juvenile trees in a closed-canopy terra-firme (CT) forest $(n=39)$

Hevea $(n=4)$ and Gustavia $(n=4)$. Those five dominant genera are also frequently observed in undisturbed terrafirme forests. For example, Iryanthera was reportedly the second most abundant genus in the undisturbed terra-firme forest in the SG site ${ }^{10}$. Each tree was manually excavated with extreme care to avoid damaging the roots. The diameters at ground basis $(D G B, \mathrm{~mm})$ and $H(\mathrm{~cm})$ were measured. However, the $D G B$ were not measured for some juvenile trees $(n=11)$ in the SG site due to accidental loss, and the $D G B$ of those juvenile trees were estimated from the diameter at $10 \%$ of the tree height (see Fig. S1). The $D B H(\mathrm{~mm})$ was measured only for large-sized juvenile trees $(n=87$ at the ZF2 site). Each sample was oven-dried at $65^{\circ} \mathrm{C}$ until a constant weight was obtained.

\section{Development of allometric models to estimate biomass}

To estimate $T M, A G M$ and $B G M(\mathrm{~kg})$, the following six models were tested considering previous studies ${ }^{7,10,14,16}$ : model 1: $\ln (M)=a+b \ln (D)$; model 2: $\ln (M)=a+b \ln$ $(H)$; model 3: $\ln (M)=a+b \ln (D)+c \ln (H)$; model 4: $M=$ $a D^{b}$; model 5: $M=a H^{b}$; and model 6: $M=a D^{b} H^{c}$, where $M$ means individual dry mass including $T M, A G M$ and $B G M$. The $D(\mathrm{~mm})$ means $D B H$ or $D G B$. Here, $a, b$ and $c$ are coefficients. For approximation, ordinary and non-linear least-square methods were applied for Models 1-3 and 4-6, respectively. To determine the best fit model, we evaluated the degree of fit by calculating the adjusted coefficient of determination $R^{2 *}$ and the standard deviation of the mean $S_{\mathrm{y} . \mathrm{x} \%}\left(=\frac{2 s}{\bar{y} \sqrt{n}} \times 100\right.$, where $s, \bar{y}$ and $n$ are the standard 
Table 1. Coefficients and statistics of six allometric models (1-6) for estimating the biomass component, individual total dry mass TM, aboveground dry mass $A G M$ and belowground dry mass $B G M$ with explanatory variables of diameter at ground basis $D G B$ and tree height $H$ in the $\mathrm{ZF} 2$ site

\begin{tabular}{|c|c|c|c|c|c|c|}
\hline Models for $A G M, n=215$ & $a$ & $b$ & $c$ & $C F$ & $R^{2^{*}}$ & $S_{\mathrm{y} \cdot \mathrm{x} \%}$ \\
\hline 1: $\ln (A G M)=a+b \ln (D G B)$ & $-1.374( \pm 0.199)$ & $2.311( \pm 0.808)$ & & 1.123 & 0.772 & 4.772 \\
\hline $2: \ln (A G M)=a+b \ln (H)$ & $-6.490( \pm 0.494)$ & $2.054( \pm 0.094)$ & & 1.190 & 0.486 & 7.173 \\
\hline 3: $\ln (A G M)=a+b \ln (D G B)+c \ln (H)$ & $-3.842( \pm 0.422)$ & $1.645( \pm 0.127)$ & $0.782( \pm 0.121)$ & 1.102 & 0.762 & 4.882 \\
\hline 4: $A G M=a D G B^{b}$ & $0.161( \pm 0.051)$ & $2.507( \pm 0.098)$ & & 1.000 & 0.781 & 4.686 \\
\hline 5: $A G M=a H^{b}$ & $0.001( \pm 0.001)$ & $2.104( \pm 0.174)$ & & 1.000 & 0.49 & 7.146 \\
\hline 6: $A G M=a D G B^{b} H^{c}$ & $0.025( \pm 0.018)$ & $2.218( \pm 0.133)$ & $0.473( \pm 0.159)$ & 1.000 & 0.792 & 4.600 \\
\hline Models for $B G M, n=215$ & $a$ & $b$ & $c$ & $C F$ & $R^{2^{*}}$ & $S_{\mathrm{y} \cdot \mathrm{x} \%}$ \\
\hline $1: \ln (B G M)=a+b \ln (D G B)$ & $-2.643( \pm 0.259)$ & $2.147( \pm 0.105)$ & & 1.218 & 0.564 & 7.233 \\
\hline $2: \ln (B G M)=a+b \ln (H)$ & $-6.133( \pm 0.677)$ & $1.667( \pm 0.129)$ & & 1.386 & 0.286 & 9.260 \\
\hline 3: $\ln (B G M)=a+b \ln (D G B)+c \ln (H)$ & $-2.703( \pm 0.603)$ & $2.131( \pm 0.181)$ & $0.019( \pm 0.172)$ & 1.218 & 0.562 & 7.253 \\
\hline 4: $B G M=a D G B^{b}$ & $0.044( \pm 0.021)$ & $2.394( \pm 0.148)$ & & 1.000 & 0.579 & 7.110 \\
\hline 5: $B G M=a H^{b}$ & $0.001( \pm 0.001)$ & $1.843( \pm 0.220)$ & & 1.000 & 0.296 & 9.197 \\
\hline 6: $B G M=a D G B^{b} H^{c}$ & $0.063( \pm 0.064)$ & $2.456( \pm 0.222)$ & $0.096( \pm 0.245)$ & 1.000 & 0.578 & 7.124 \\
\hline Models for $T M, n=504$ & $a$ & $b$ & $c$ & $C F$ & $R^{2^{*}}$ & $S_{y . x \%}$ \\
\hline 1: $\ln (T M)=a+b \ln (D G B)$ & $-1.819( \pm 0.084)$ & $2.515( \pm 0.041)$ & & 1.127 & 0.813 & 4.266 \\
\hline 2: $\ln (T M)=a+b \ln (H)$ & $-5.383( \pm 0.179)$ & $1.878( \pm 0.039)$ & & 1.196 & 0.552 & 6.606 \\
\hline 3: $\ln (T M)=a+b \ln (D G B)+\operatorname{cln}(H)$ & $-3.531( \pm 0.151)$ & $1.669( \pm 0.074)$ & $0.744( \pm 0.057)$ & 1.094 & 0.795 & 4.465 \\
\hline 4: $T M=a D G B^{b}$ & $0.178( \pm 0.035)$ & $2.528( \pm 0.061)$ & & 1.000 & 0.813 & 4.262 \\
\hline 5: $T M=a H^{b}$ & $0.002( \pm 0.001)$ & $2.059( \pm 0.106)$ & & 1.000 & 0.569 & 6.482 \\
\hline 6: $T M=a D G B^{b} H^{c}$ & $0.044( \pm 0.018)$ & $2.251( \pm 0.089)$ & $0.392( \pm 0.099)$ & 1.000 & 0.819 & 4.198 \\
\hline
\end{tabular}

Each coefficient (a-c) is shown with SE in parentheses. The degree of fitness is indicated by the adjusted coefficient of determination $R^{2^{*}}$ and the standard deviation of the mean $S_{y . x \%}$. The correction factor CF to reduce the bias of log-transformation is shown for Models 1-3.

deviation of the regression, mean of focal variable and the number of samples, respectively). The $R^{2^{*}}$ and $S_{\mathrm{y} . \mathrm{x} \%}$ for Models 1-3 were calculated based on back-transformed data. To correct the bias introduced by log-transformed data, a correction factor $C F$ was calculated as follows ${ }^{17}$ : $C F=\exp \left(s^{2} / 2\right)$. Although the Akaike's Information Criterion AIC was also calculated, the results were not shown since the results of AIC were similar to those based on $R^{2^{*}}$ and $S_{\mathrm{y} . \mathrm{x} \%}$. All regression analyses were conducted using statistical software R ver. 2.14.0.

\section{Comparisons of allometric models between open- and closed-canopy forests}

To confirm the generality of the allometric models developed for juvenile trees in the open-canopy terra-firme forest (OT) at the ZF2 site, the models were compared with those for juvenile trees in the closed-canopy terra-firme forest (CT) at the SG site $(n=50)$. A comparison was performed for the relationships of $A G M, B G M$ and $T M$ to $D G B$ according to the analysis of covariance (ANCOVA). The ANCOVA was performed after log-transformation of the variables, i.e. Model 1 compared two different forest types for each biomass component. Similarly, the $D G B-H$ and $A G M-B G M$ relationships were also compared with those from the SG site.

\section{Results and Discussion}

Six models were evaluated for each biomass component in the open-canopy terra-firme forest (OT) at the ZF2 site (Table 1) and the closed-canopy terra-firme forest (CT) in the SG site (Table 2). For $T M$ and $A G M$, Models 3 and 6 with $D G B$ achieved the highest $R^{2^{*}}$ and the lowest $S_{y, x}$ in each site. For $B G M$, Model 4 achieved the highest $R^{2 *}$ and lowest $S_{y, x \%}$ in each site. Interestingly, $H$ did not improve the fitting for estimating $B G M$, i.e. Model 6 including $H$ showed lower $R^{2 *}$ and higher $S_{y, x \%}$ than Model 4. Model 4 could be applied without $H$ measurement and thus showed superior working efficiency to the other models requiring $H$ measurement. Although $H$ did not improve the fitting for each biomass component in the OT forest, $H$ improved the fitting for $A G M$ and $T M$ in the CT forest. In terms of general versatility and accuracy of the model, it was concluded that the best models were 6 for estimating $A G M$ and $T M$, and 4 for estimating $B G M$ in the present study sites.

Using 87 samples $(H>2 \mathrm{~m})$ in the OT forest, allometric models with $D B H$ were also compared to those 
Table 2. Coefficients and statistics of six allometric models (1-6) for estimating the biomass component, individual total dry mass $T M$, aboveground dry mass $A G M$ and belowground dry mass $B G M$ with explanatory variables of diameter at ground basis $D G B$ and tree height $H$ in the SG site

\begin{tabular}{|c|c|c|c|c|c|c|}
\hline Models for $A G M, n=50$ & $a$ & $b$ & $c$ & $C F$ & $R^{2^{*}}$ & $S_{\mathrm{y} . \mathrm{x} \%}$ \\
\hline 1: $\ln (A G M)=a+b \ln (D G B)$ & $-10.648( \pm 0.183)$ & $3.028( \pm 0.067)$ & & 1.103 & 0.854 & 11.59 \\
\hline $2: \ln (A G M)=a+b \ln (H)$ & $-3.912( \pm 0.088)$ & $2.584( \pm 0.076)$ & & 1.185 & 0.872 & 10.83 \\
\hline 3: $\ln (A G M)=a+b \ln (D G B)+c \ln (H)$ & $-8.265( \pm 0.497)$ & $1.950( \pm 0.221)$ & $0.958( \pm 0.190)$ & 1.067 & 0.930 & 8.04 \\
\hline 4: $A G M=a D G B^{b}$ & $0.0003( \pm 0.0004)$ & $2.383( \pm 0.307)$ & & 1.000 & 0.901 & 9.52 \\
\hline 5: $A G M=a H^{b}$ & $0.023( \pm 0.012)$ & $2.717( \pm 0.249)$ & & 1.000 & 0.932 & 7.90 \\
\hline $6: A G M=a D G B^{b} H^{c}$ & $0.003( \pm 0.003)$ & $0.931( \pm 0.323)$ & $1.881( \pm 0.316)$ & 1.000 & 0.943 & 7.25 \\
\hline Models for $B G M, n=50$ & $a$ & $b$ & $c$ & $C F$ & $R^{2^{*}}$ & $S_{\mathrm{y} \cdot \mathrm{x} \%}$ \\
\hline $1: \ln (B G M)=a+b \ln (D G B)$ & $-10.799( \pm 0.285)$ & $2.616( \pm 0.104)$ & & 1.269 & 0.316 & 23.81 \\
\hline $2: \ln (B G M)=a+b \ln (H)$ & $-4.981( \pm 0.112)$ & $2.238( \pm 0.097)$ & & 1.320 & 0.656 & 16.89 \\
\hline $3: \ln (B G M)=a+b \ln (D G B)+c \ln (H)$ & $-8.531( \pm 0.895)$ & $1.591( \pm 0.399)$ & $0.911( \pm 0.343)$ & 1.236 & 0.522 & 19.91 \\
\hline 4: $B G M=a D G B^{b}$ & $0.002( \pm 0.002)$ & $1.531( \pm 0.274)$ & & 1.000 & 0.714 & 15.39 \\
\hline 5: $B G M=a H^{b}$ & $0.023( \pm 0.016)$ & $1.759( \pm 0.339)$ & & 1.000 & 0.677 & 16.36 \\
\hline 6: $B G M=a D G B^{b} H^{c}$ & $0.001( \pm 0.001)$ & $1.853( \pm 0.595)$ & $-0.360( \pm 0.547)$ & 1.000 & 0.710 & 15.51 \\
\hline Models for $T M, n=50$ & $a$ & $b$ & $c$ & $C F$ & $R^{2^{*}}$ & $S_{\mathrm{y} \cdot \mathrm{x} \%}$ \\
\hline 1: $\ln (T M)=a+b \ln (D G B)$ & $-10.136( \pm 0.191)$ & $2.944( \pm 0.070)$ & & 1.113 & 0.826 & 12.34 \\
\hline $2: \ln (T M)=a+b \ln (H)$ & $-3.588( \pm 0.090)$ & $2.511( \pm 0.077)$ & & 1.193 & 0.890 & 9.819 \\
\hline 3: $\ln (T M)=a+b \ln (D G B)+\operatorname{cln}(H)$ & $-7.851( \pm 0.540)$ & $1.910( \pm 0.241)$ & $0.918( \pm 0.207)$ & 1.080 & 0.922 & 8.261 \\
\hline 4: $T M=a D G B^{b}$ & $0.001( \pm 0.001)$ & $2.204( \pm 0.264)$ & & 1.000 & 0.905 & 9.119 \\
\hline 5: $T M=a H^{b}$ & $0.035( \pm 0.018)$ & $2.577( \pm 0.237)$ & & 1.000 & 0.928 & 7.919 \\
\hline 6: $T M=a D G B^{b} H^{c}$ & $0.006( \pm 0.006)$ & $0.883( \pm 0.316)$ & $1.705( \pm 0.317)$ & 1.000 & 0.938 & 7.348 \\
\hline
\end{tabular}

Each coefficient (a-c) is shown with SE in parentheses. The degree of fitness is indicated by the adjusted coefficient of determination $R^{2^{*}}$ and the standard deviation of the mean $S_{\mathrm{y} \times \mathrm{\%} \%}$. The correction factor CF to reduce the bias of log-transformation is shown for Models 1-3.

with $D G B$ (Table 3). Overall, models with $D B H$ showed poor fitting results compared to those with $D G B$ in each case, i.e. $D B H$-based models showed lower $R^{2^{*}}$ and higher $S_{y, x \%}$ than corresponding models based on $D G B$. Although $D G B$ showed higher accuracy for estimating dry mass, the use of $D G B$ would be inconvenient for relatively large trees. This is because stems tend to be shaped irregularly near the ground, which results in inaccuracy when estimating the dry mass of large trees, especially those with buttresses. Therefore, the use of $D G B$ can only be recommended for juvenile trees.

To confirm the generality of developed models for open-canopy terra-firme forest, the models were compared with those from the closed-canopy terra-firme forest at the CT forest. As depicted in Fig. 1, the DGB - $A G M$ relationships differed significantly between them (slope, $F_{1,259}=$ $\left.44.82, p=1.32 \times 10^{-10}<0.001\right)$. Within the observed range of $D G B$, the $A G M$ for a given $D G B$ tended to be higher in the open-canopy forest than in the closed-canopy forest. Conversely, the $D G B$ - $B G M$ relationship did not differ significantly between them (slope, $F_{1,259}=10.56, p=0.0013>$ 0.001 ; intercept $F_{1,260}=0.578, p=0.448>0.05$ ). Consequently, the $D G B-T M$ relationship showed a significant difference (slope, $F_{1,551}=6.01, p=6.32 \times 10^{-09}<$
0.001).

The $A G M$ and $T M$ at a given $D G B$ were higher in the open-canopy forest than in the closed-canopy forest, which is partly attributable to the differences in $H$, since the $H$ at a given $D G B$ was significantly higher in the open- rather than closed-canopy forest (Fig. 2a), i.e. the $D G B-H$ relationship differed significantly in the intercept with a common slope (slope, $F_{1,550}=0.042, p=0.839>0.05$; intercept $F_{1,551}=$ 18.02, $\left.p=2.57 \times 10^{-5}<0.001\right)$. Light-demanding species tend to be taller than shade-tolerant species for a given diameter ${ }^{6,8,13}$ since the former grow rapidly to reach the canopy and gain a competitive advantage in the struggle for light. It has been reported that the differences in size between functional types were only present in the early stages of plant development ${ }^{2}$. The present study also confirmed that the difference in the $D G B-A G M$ relationships became unclear with increasing size (Fig. 1a).

In addition, the $A G M-B G M$ relationship also showed significant difference in the intercept with a common slope (Fig. 2b) (slope, $F_{1,259}=0.001, p=0.977>0.05$; intercept $\left.F_{1,260}=26.163, p=6.097 \times 10^{-7}<0.001\right)$, and the $B G M$ for a given $A G M$ was lower in the open- rather than closed-canopy forest. Similarly, light-demanding species reportedly show a lower root/ shoot ratio than shade-tolerant spe- 
Table 3. Comparisons of four allometric models (1, 3, 4 and 6) based on $D G B$ and $D B H$ for estimating the biomass component, including individual total dry mass $T M$, aboveground dry mass $A G M$ and belowground dry mass $B G M$ in the $\mathrm{ZF2}$ site

\begin{tabular}{|c|c|c|c|c|c|c|}
\hline Models for $A G M$ with $D B H, n=87$ & $a$ & $b$ & $c$ & $C F$ & $R^{2^{*}}$ & $S_{\mathrm{y} \cdot \mathrm{x} \%}$ \\
\hline $1: \ln (A G M)=a+b \ln (D B H)$ & $1.144( \pm 0.351)$ & $1.618( \pm 0.141)$ & & 1.138 & 0.531 & 7.308 \\
\hline 3: $\ln (A G M)=a+b \ln (D B H)+c \ln (H)$ & $0.235( \pm 1.708)$ & $1.315( \pm 0.231)$ & $0.211( \pm 0.375)$ & 1.140 & 0.528 & 7.332 \\
\hline 4: $A G M=a D B H^{b}$ & $1.660( \pm 0.967)$ & $1.901( \pm 0.195)$ & & 1.000 & 0.548 & 7.173 \\
\hline 6: $A G M=a D B H^{b} H^{c}$ & $0.267( \pm 0.494)$ & $1.774( \pm 0.236)$ & $0.374( \pm 0.360)$ & 1.000 & 0.549 & 7.166 \\
\hline Models for $B G M$ with $D B H, n=87$ & $a$ & $b$ & $c$ & $C F$ & $R^{2^{*}}$ & $S_{\mathrm{y}, \mathrm{x} \%}$ \\
\hline $1: \ln (B G M)=a+b \ln (D B H)$ & $-0.627( \pm 0.549)$ & $1.596( \pm 0.218)$ & & 1.368 & 0.327 & 10.317 \\
\hline 3: $\ln (B G M)=a+b \ln (D B H)+c \ln (H)$ & $0.212( \pm 2.643)$ & $1.688( \pm 0.358)$ & $-0.189( \pm 0.580)$ & 1.367 & 0.321 & 10.567 \\
\hline 4: $B G M=a D B H^{b}$ & $0.349( \pm 0.298)$ & $1.859( \pm 0.287)$ & & 1.000 & 0.334 & 10.458 \\
\hline $6: B G M=a D B H^{b} H^{c}$ & $0.608( \pm 1.655)$ & $1.896( \pm 0.347)$ & $-0.113( \pm 0.539)$ & 1.000 & 0.327 & 10.518 \\
\hline Models for $T M$ with $D B H, n=87$ & $a$ & $b$ & $c$ & $C F$ & $R^{2^{*}}$ & $S_{\mathrm{y} \cdot \mathrm{x} \%}$ \\
\hline $1: \ln (T M)=a+b \ln (D B H)$ & $1.330( \pm 0.365)$ & $1.611( \pm 0.145)$ & & 1.148 & 0.515 & 7.480 \\
\hline 3: $\ln (T M)=a+b \ln (D B H)+c \ln (H)$ & $0.720( \pm 1.761)$ & $1.545( \pm 0.238)$ & $0.137( \pm 0.386)$ & 1.149 & 0.51 & 7.515 \\
\hline 4: $T M=a D B H^{b}$ & $2.005( \pm 1.198)$ & $1.894( \pm 0.200)$ & & 1.000 & 0.531 & 7.353 \\
\hline 6: $T M=a D B H^{b} H^{c}$ & $0.466( \pm 0.887)$ & $1.794( \pm 0.242)$ & $0.299( \pm 0.371)$ & 1.000 & 0.529 & 7.367 \\
\hline Models for $A G M$ with $D G B, n=87$ & $a$ & $b$ & $c$ & $C F$ & $R^{2^{*}}$ & $S_{\mathrm{y} \cdot \mathrm{x} \%}$ \\
\hline $1: \ln (A G M)=a+b \ln (D G B)$ & $-0.760( \pm 0.429)$ & $2.125( \pm 0.153)$ & & 1.106 & 0.678 & 6.046 \\
\hline 3: $\ln (A G M)=a+b \ln (D G B)+c \ln (H)$ & $-2.903( \pm 1.212)$ & $1.870( \pm 0.202)$ & $0.504( \pm 0.267)$ & 1.103 & 0.683 & 6.005 \\
\hline 4: $A G M=a D G B^{b}$ & $0.180( \pm 0.105)$ & $2.474( \pm 0.181)$ & & 1 & 0.698 & 5.860 \\
\hline 6: $A G M=a D G B^{b} H^{c}$ & $0.017( \pm 0.024)$ & $2.249( \pm 0.212)$ & $0.526( \pm 0.289)$ & 1 & 0.706 & 5.781 \\
\hline Models for $B G M$ with $D G B, n=87$ & $a$ & $b$ & $c$ & $C F$ & $R^{2^{*}}$ & $S_{\mathrm{y} \cdot \mathrm{x} \%}$ \\
\hline $1: \ln (B G M)=a+b \ln (D G B)$ & $-3.360( \pm 0.621)$ & $2.402( \pm 0.221)$ & & 1.239 & 0.477 & 9.263 \\
\hline 3: $\ln (B G M)=a+b \ln (D G B)+c \ln (H)$ & $-2.249( \pm 1.788)$ & $2.535( \pm 0.298)$ & $-0.261( \pm 0.339)$ & 1.238 & 0.472 & 9.312 \\
\hline 4: $B G M=a D G B^{b}$ & $0.042( \pm 0.379)$ & $2.411( \pm 0.281)$ & & 1.000 & 0.478 & 9.263 \\
\hline $6: B G M=a D G B^{b} H^{c}$ & $0.092( \pm 0.206)$ & $2.487( \pm 0.359)$ & $-0.177( \pm 0.468)$ & 1.000 & 0.473 & 9.310 \\
\hline Models for $T M$ with $D G B, n=87$ & $a$ & $b$ & $c$ & $C F$ & $R^{2^{*}}$ & $S_{y . x \%}$ \\
\hline $1: \ln (T M)=a+b \ln (D G B)$ & $-0.686( \pm 0.426)$ & $2.159( \pm 0.151)$ & & 1.105 & 0.673 & 6.134 \\
\hline $3: \ln (T M)=a+b \ln (D G B)+c \ln (H)$ & $-2.317( \pm 0.215)$ & $1.965( \pm 0.203)$ & $0.383( \pm 0.267)$ & 1.104 & 0.675 & 6.124 \\
\hline 4: $T M=a D G B^{b}$ & $0.221( \pm 0.132)$ & $2.464( \pm 0.184)$ & & 1.000 & 0.688 & 5.994 \\
\hline 6: $T M=a D G B^{b} H^{c}$ & $0.033( \pm 0.049)$ & $2.284( \pm 0.221)$ & $0.421( \pm 0.298)$ & 1.000 & 0.692 & 5.960 \\
\hline
\end{tabular}

Each coefficient (a-c) is shown with $95 \%$ confidence intervals in parentheses. The degree of fitness is indicated by the adjusted coefficient of determination $R^{2^{*}}$ and the standard deviation of the mean $S_{\mathrm{y} . \mathrm{x} \%}$. The correction factor CF to reduce the bias of logtransformation is shown for Models 1 and 3.

$\operatorname{cies}^{4,9,15}$. The low root / shoot ratio in the light-demanding species may also be partly attributable to the rapid height growth of light-demanding species to gain a competitive advantage in the struggle with neighboring trees for light ${ }^{6,8,13}$.

\section{Acknowledgements}

The authors would like to thank all members of the international cooperative research project of Carbon Dynamics of Amazonian Forests, and Drs. K. Niiyama and K. Tanaka for their valuable suggestions. This study was financially supported by the Research Support Foundation of the Amazon State (FAPEAM), the INCT-Amazon Wood and the Science and the Technology Research Partnership for Sustainable Development program of the Japan Science and Technology Agency and the Japan International Cooperation Agency.

\section{References}

1. APG III. (2009) An update of the Angiosperm Phylogeny Group classification for the orders and families of flowering plants: APG III. Bot. J. Linnean Soc., 161, 105-121.

2. Bohlman, S. \& O'Brien, S. (2006) Allometry, adult stature and regeneration requirement of 65 tree species on Barro Colorado Island, Panama. J. Trop. Ecol., 22, 123-136.

3. Brown, S. (2002) Measuring carbon in forests: current status and future challenges. Environ. Pollut., 116, 363-372. 

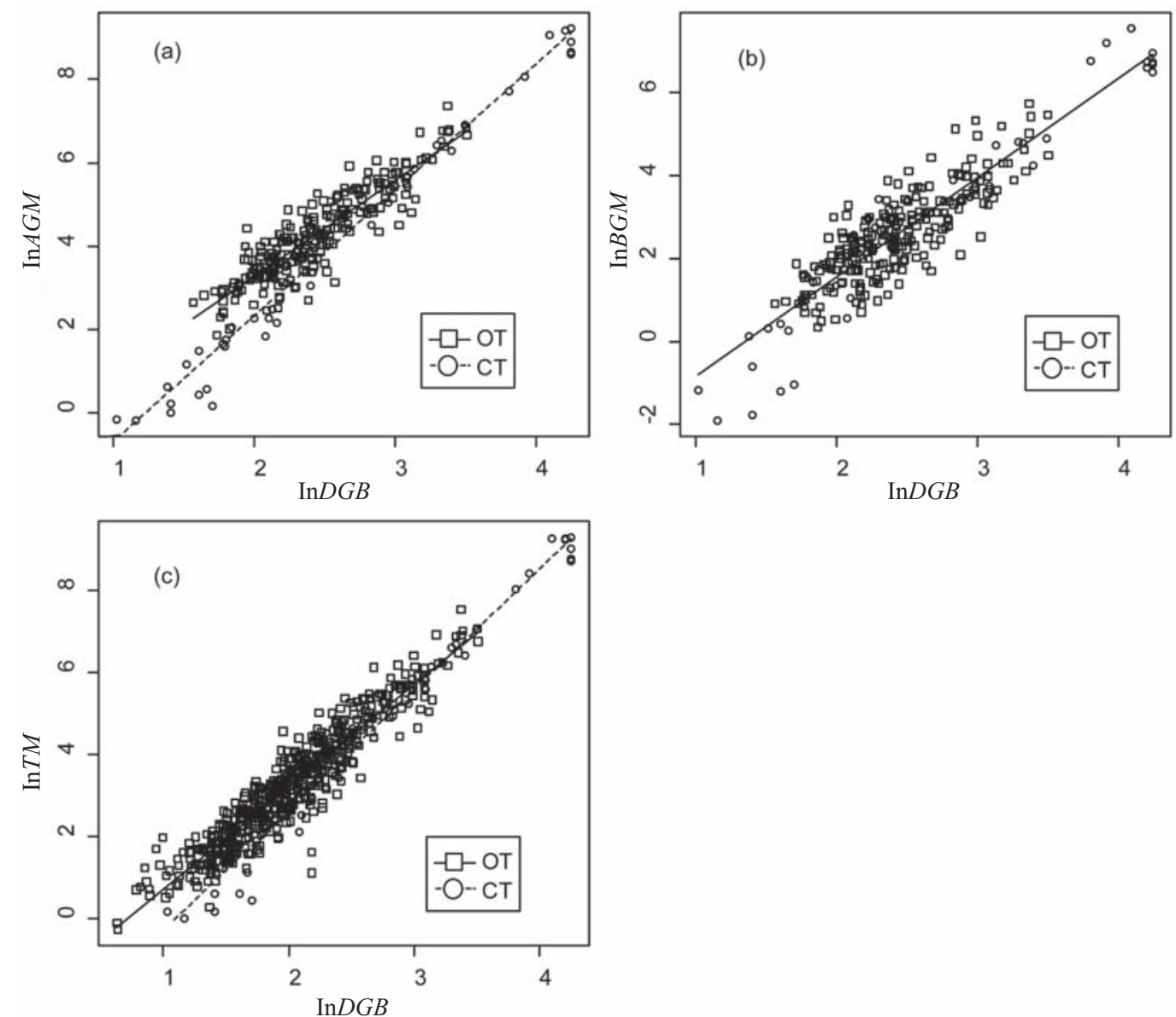

Fig. 1. The relationships between logarithms of diameter at ground basis $D G B[\mathrm{~mm}]$ and biomass components including (a) aboveground dry mass $A G M[\mathrm{~g}]$, (b) belowground dry mass $B G M[\mathrm{~g}]$ and (c) total dry mass $T M[\mathrm{~g}]$ for two different forest types

The circles and squares indicate data from open- and closed-canopy terra-firme forests (OT and CT) respectively. The solid and dashed lines in figures (a) and (c) mean regression lines for OT and CT, respectively. The solid line in Figure (b) means the common regression line for OT and CT.
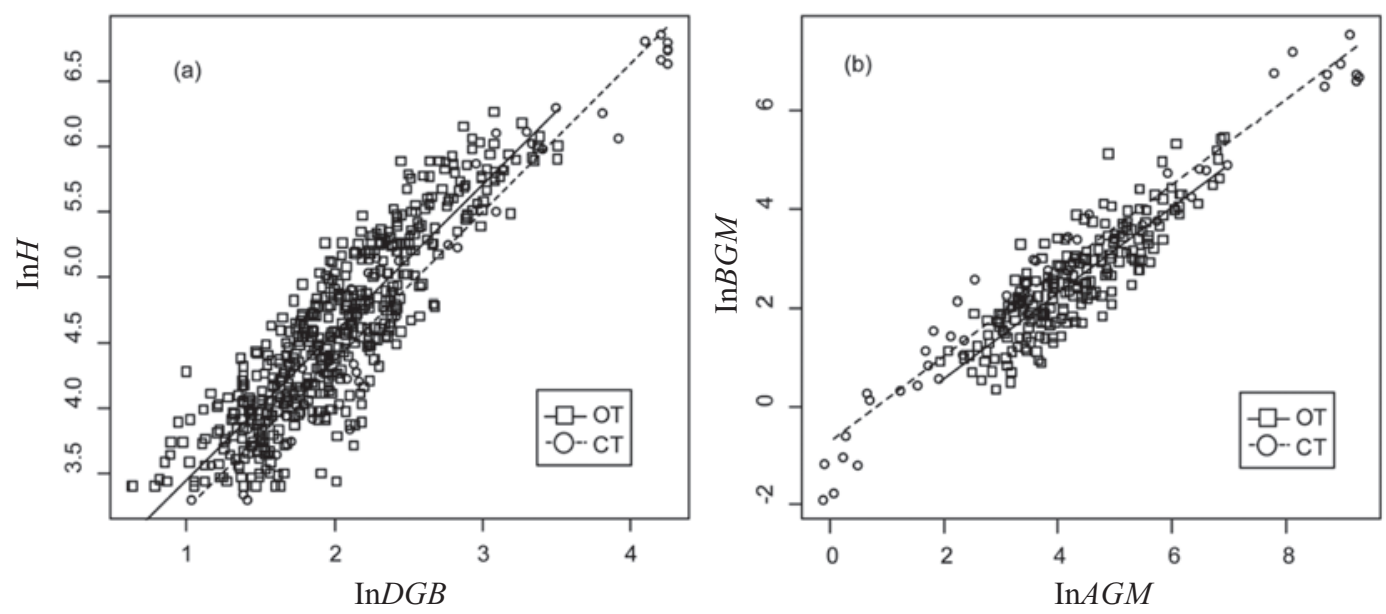

Fig. 2. (a)The relationships between logarithms of diameter at ground basis $D G B[\mathrm{~mm}]$ and tree height $H$ [cm], and (b) The relationships between logarithms of individual aboveground and belowground dry mass $A G M$ and $B G M[g]$ respectively for two study sites

The circles and squares indicate data from open-canopy terra-firme and closed-canopy terra-firme forests (OT and CT). The solid and dashed lines mean regression lines for OT and CT, respectively. 
4. Cao, K.-F. \& Ohkubo, T. (1998) Allometry, root/shoot ratio and root architecture in understory saplings of deciduous dicotyledonous trees in central Japan. Ecol. Res., 13, 217 227.

5. Chambers, J. Q. et al. (2004) Response of tree biomass and wood litter to disturbance in a central Amazon forest. Oecologia, 141, 596-611.

6. Coll, L. et al. (2008) Root architecture and allocation patterns of eight native tropical species with different successional status used in open-grown mixed plantations in Panama. Trees Struc. Func., 22, 585-596.

7. Higuchi, N. et al. (1998) Biomassa da parte aérea da vegetação da floresta úmida de terra-firme da Amazônia brasileira. Acta Amazônica, 28, 153-166.

8. King, D.A. (1991) Correlations between biomass allocation, relative growth rate and light environment in tropical forest saplings. Funct. Ecol., 5, 485-492.

9. Kitajima, K. (1994) Relative importance of photosynthetic traits and allocation patterns as correlates of seedling shade tolerance of 13 tropical trees. Oecologia, 98, 419-428.

10. Lima, J.N.A. et al. (2012). Allometric models for estimating above- and below-ground biomass of tropical rainforests at São Gabriel da Cachoeira in upper Rio Negro, Brazilian Amazon. Forest Ecol.Manage., 277, 163-172.

11. Negrón-Juárez, R.I. et al. (2010) Widespread Amazon forest tree mortality from a single cross-basin squall line event. Geophy. Res. Letters., 37, L16701, doi:10.1029/2010GL 043733.

12. Nelson, B.W. et al. (1999) Allometric regressions for improved estimate of secondary forest biomass in the central Amazon. Forest Ecol. Manage., 117, 149-167.

13. Porter, L. et al. (2003) Architecture of 53 rain forest tree species differing in adult stature and shade tolerance. Ecology, 84, 602-608.

14. Santos, J. (1996) Analize de modelos de regressao para estimar a fitomass de floresta tropical umida de terra-firme de Amazonia Brasiliera. Ph.D. Dissertation, Universidade Federal de Vicosa, Minas Gerais, Brazil, pp. 121 [In Portuguese with English abstract].

15. Shukla, R.P. \& Ramakrishnan, P.S. (1984) Leaf dynamics of tropical trees related to successional status. New Phytol., 97, 697-706.

16. Silva, R.P. (2007) Alometria, estoque e dinâmica da biomassa de florestas primárias e secundárias na regiaõ de Manaus (AM). Ph.D. Dissertation, Universidade Federal do Amazonas, Manaus, Brazil, pp. 152 [In Portuguese with English abstract].

17. Sprugel, D.G. (1983) Correcting for bias in log-transformed allometric equations. Ecology, 64, 209-210. 